\title{
INDUSTRY RISK ASSESSMENT IN BRAZIL WITH THE AHP
}

\author{
Bernardo Brazao Rego Mello \\ Ibmec/RJ and BNDES \\ Rio de Janeiro, Brazil \\ E-mail: bernardo.brazao@bndes.gov.br \\ Sergio Augusto Novis Filho \\ Ibmec/RJ and BNDES \\ Rio de Janeiro, Brazil \\ E-mail: snovis@bndes.gov.br \\ Luiz Flavio Autran Monteiro Gomes \\ Ibmec/RJ \\ Rio de Janeiro, Brazil \\ E-mail: autran@ibmecrj.br
}

\begin{abstract}
With the increasing importance of the financial market over the past decades, credit risk has become paramount in investment evaluation, loan spreads, corporate solvency, growth prospects, etc. Credit risk evaluation models may be classified into two broad categories: quantitative and qualitative. Quantitative models consider financial statements and indexes, while qualitative models analyze the systemic variables that affect corporate business. These models typically follow a top-down approach and consist of analyzing the industries and going deep into the managerial structure. The aim of this paper is to present an industry risk model that can prioritize variables according to their importance and group them by their nature. The model is based on Analytic Hierarchy Process method and leads to an industry risk score and rating that can be useful to industry risk assessment. By applying it to three different industries in Brazil (pharmaceutical, information technology and airline), the obtained ratings show a strong coherent in terms of a credit risk perspective.
\end{abstract}

Keywords: industry risk, credit risk, industrial analysis, Analytic Hierarchy Process.

\section{Introduction}

The current environment of uncertainties brings many challenges to organizations and generates constant pressure to reduce business risk. The greater the importance and complexity of the decision for the positioning of the organization, the greater the benefit of informed decision making.

One of the most important challenges is to measure the impact of the qualitative variables that affect business. The difficulty lies in quantifying these variables and transforming them into tangible indexes that represent coherent results for the organization.

In this paper a model based on Analytic Hierarchy Process (AHP) is introduced that allows evaluating the variables affecting different industries. Such model can then be 
IJAHP Article: Mello, Novis Filho, Gomes/Industry Risk Assessment in Brazil with the AHP To Be Submitted to the International Symposium of the Analytic Hierarchy Process 2014, Washington D.C., U.S.A.

used to measure the level of industry risk through a credit risk perspective. It is explained how the chosen multi-criteria method can be useful to determine weights according to the importance of each variable to the system, prioritizing them and, as a result, assigning a level of risk to the analyzed industry.

\section{Literature Review}

The credit risk study field is wide enough to encompass both quantitative and qualitative analyses. While the first includes financial indexes, estimates of loss given default and probability of default, the latter covers studies focusing on quantifying the qualitative variables that affect the industries.

Multi-criteria decision analysis can be used whenever one wishes to select, order, classify or describe alternatives present in a decision process in the presence of multiple criteria quantitative and qualitative (Zopounidis and Pardalos, 2010). This indicates the potential for application of multi-criteria methods as valuable tools in the analysis of industry risk. From a credit risk perspective, the "industry analysis shows how diverse and different forces act on an industry impacting its survival and profitability and indicates the fate of players in it". Besides, an "Intelligent classification of industry is vital for the study of credit risk of an obligor as it facilitates proper understanding of the peer group and industry dynamics" (Joseph, 2013).

"In fact, identifying the inherent industry risks gives the credit analyst a starting point for the interrogation of a specific company and its particular credit risks" (Gangun and Bilardello, 2005). This understanding reinforces the main purpose of the paper, because studying the industry risk is the beginning of any well-grounded credit risk analysis.

\section{Hypotheses/Objectives}

The objective behind this paper is to propose an industry risk analytical model that allows evaluating the variables impacting on the several industries of the Brazilian economy.

In order to develop this model, the AHP is used. This model leads to prioritizing each set of variables according to its importance to the industry risk. These variables are then grouped in key factors according to their nature. The application of such model, as well as the variables and factors, are outlined in the following sections.

\section{Research Design/Methodology}

The basis for the development of the model lies in the intrinsic characteristics of the industry risk analysis. The variables considered in the determination of the priorities and further categorizations are those that should be usually observed when evaluating any industry.

The variable prioritization and posterior categorization is based on the AHP. Applying this multi-criteria method, it is possible to determine the importance and thus classifying each variable in the industry risk system.

With the help of expert credit risk analysts from the major public Brazilian bank of economic and social development, the list of variables and their priorities are then determined.

As an example, to illustrate how the AHP method can be useful to assist the industry risk assessment in a clear and objective manner, a partial study is included in this paper. In 
IJAHP Article: Mello, Novis Filho, Gomes/Industry Risk Assessment in Brazil with the AHP To Be Submitted to the International Symposium of the Analytic Hierarchy Process 2014, Washington D.C., U.S.A.

this partial study three industries are considered: pharmaceutical, information technology and airline.

Inconsistency values are computed for each set of variables. All such values remain below $10 \%$, which suggests that the obtained model is consistent and therefore can be used to assess the industry risk.

\section{Data/Model Analysis}

The industry risk assessment model is composed of six sets of variables that are grouped according to their natures. The first set includes variables regarding the competition level: industry concentration, price and margin pressures, entry barriers and threat of substitute products. The second set comprises the stability level: historical cash generation, cash generation prospect and industry demand. The third concerns the growth prospect: historical growth and growth potential. The fourth has directly to do with infrastructure: logistics, energy and telecommunication; human resources and technological resources for providing infrastructure. The fifth is related to regulation and public policies. The sixth covers macroeconomic and environmental factors: business cycle, fiscal and monetary policies, environmental factors, inflation and exchange rate volatility.

Table 1 presents the sets of variables and the credit risk evaluation of their relative importance by the analysts. Figures in table 1 are later used to determine the order of priorities in the system. Table 2 presents the set of variables that are chosen to assess industry risk.

Table 1 - Set of variables and pairwise comparison

\begin{tabular}{|l|c|c|c|c|c|c|}
\hline \multicolumn{1}{|c|}{ Set of variables } & 1 & 2 & 3 & 4 & 5 & 6 \\
\hline 1 - Competition Level & & 1 & 3 & 5 & 5 & 3 \\
\hline 2- Stability Level & & & 3 & 5 & 5 & 3 \\
\hline 3 - Growth Prospect & & & & 5 & 5 & 1 \\
\hline 4- Infrastructure & & & & & 1 & $1 / 3$ \\
\hline 5 - Government Acts & & & & & & $1 / 3$ \\
\hline 6- Macroeconomics and Environmental Factors & & & & & & \\
\hline
\end{tabular}


IJAHP Article: Mello, Novis Filho, Gomes/Industry Risk Assessment in Brazil with the AHP To Be Submitted to the International Symposium of the Analytic Hierarchy Process 2014, Washington D.C., U.S.A.

Table 2 - All variables that are included in the model for assessing the industry risk

\begin{tabular}{|c|c|}
\hline \multirow{4}{*}{1 - Competition Level } & Concentration level \\
\hline & Price and margin pressures \\
\hline & Entry barriers \\
\hline & Threat of substitute products \\
\hline \multirow{3}{*}{2 - Stability Level } & Historical cash generation \\
\hline & Cash generation prospect \\
\hline & Industry demand \\
\hline \multirow{2}{*}{3 - Growth Prospect } & Historical growth \\
\hline & Growth potential \\
\hline \multirow{3}{*}{4 - Infrastructure } & Logistics, energy and telecommunication \\
\hline & Human resources \\
\hline & Technological resources \\
\hline \multirow{2}{*}{5 - Government Acts } & Regulation \\
\hline & Public Policies \\
\hline \multirow{5}{*}{$\begin{array}{l}6 \text { - Macroeconomic and } \\
\text { Environmental Factors }\end{array}$} & Business cycle \\
\hline & Fiscal and monetary policies \\
\hline & Environmental factors \\
\hline & Inflation \\
\hline & Exchange rate volatility \\
\hline
\end{tabular}

\section{Limitations}

During the model development, two main limitations can be identified. Firstly, there is some divergence regarding the priority orders set out by different credit risk analysts. The second limitation comes from the variables not being completely independent. This is due to the recognition that, in the industry assessment context, the degree of risk is determined by a number of facts, trends and index results that may or may not be interconnected, which may lead to a certain degree of interdependence.

\section{Conclusions}

Developing a credit risk analysis requires evaluations on different areas: financial indexes, sectorial analyses, strategy, governance, management, etc. As a final result an industry risk score and rating are presented. Those are to be used for decision making on investments in a specific corporation, for a particular marketing and loan spread scenario. This paper focuses on the industry risk essentially, which is a part of credit risk analysis as a whole. Following this approach, the use of the AHP in order to quantify the industry risk level becomes an effective tool, because it allows the analyst to prioritize and to categorize the variables according to their reliance, leading to the measurement of the risks associated to each industry. It is thus possible to obtain an industry risk score and rating for the set of industries, so that their risk level can be measured according to their characteristics. 
IJAHP Article: Mello, Novis Filho, Gomes/Industry Risk Assessment in Brazil with the AHP To Be Submitted to the International Symposium of the Analytic Hierarchy Process 2014, Washington D.C., U.S.A.

The application of an industry risk model is useful, because the method is able to prioritize variables according to their importance to the industrial system as a whole. Furthermore, the result from the analysis of three industries presented in this paper has been coherent with the experiences of Bank analysts.

For future research it would be interesting to make use of approaches that identify possible interactions between the variables. This further development will likely help credit risk analysts to have convergent judgments on the industry risk assessment.

\section{Key References}

1. Gangun, B., Bilardello, J. (2005). Fundamentals of Corporate Credit Analysis, McGraw Hill Companies, Inc., p.40.

2. Joseph, C. (2013). Advanced Credit Risk Analysis And Management, Wiley Finance Series, p.p. 61-63.

3. Silva, A.C.S., Belderrain, M.C.N., Pantoja, F.C.M. Priorization of R\&D Projects in the Aerospace Sector, Vol.2, N³, pp. 339-348, Sep.-Dec., 2010.

4. Zopounidis, C., Pardalos, P.M., eds. (2010). Handbook of Multicriteria Analysis, Springer. 